\title{
Sistem Pendukung Keputusan Pemilihan Supplier Bahan Bangunan Menggunakan Metode Weight Product pada PT. Cipta Arsigriya
}

\author{
Agnes Mareta ${ }^{1)}$, Arie Yandi Saputra ${ }^{2)}$ \\ ${ }^{1,2}$ Program Studi Sistem Informasi STMIK Bina Nusantara Jaya Lubuklinggau \\ Jl. Yos Sudarso No.97A Kota Lubuklinggau Sumatera Selatan \\ Telp : (0733) 322307 \\ E-mail : agnes_mareta@gmail.com ${ }^{1)}$, arielahat@gmail.com ${ }^{2)}$
}

\begin{abstract}
Supplier selection is one of the most important things in purchasing activities for a company, because the selection of this supplier has a big influence on the quality and availability of a product. The main objective of the supplier selection process is to determine which suppliers have efficiency in meeting the needs of the company consistently and minimize the risks associated with the procurement of raw materials and components. Therefore, companies must choose suppliers carefully and precisely so as not to harm the company in the future. The selection of suppliers at PT Cipta Arsigriya is carried out by the purchasing department by following up on offers of cooperation from suppliers addressed to the company. This is due to shortening the process of selecting suppliers so far only based on the lowest prices and payment methods so that other factors are ignored. The neglect of these other factors causes frequent obstacles, especially in the process of building housing in companies.
\end{abstract}

Keywords:Wight Product, SPK, Building Material

\begin{abstract}
Abstrak
Pemilihan supplier merupakan salah satu hal yang penting dalam aktivitas pembelian bagi perusahaan, karena pemilihan supplier ini sangat berpengaruh pada kualitas dan ketersediaan suatu produk. Tujuan utama proses pemilihan supplier adalah untuk menentukan supplier yang memiliki efisiensi dalam memenuhi kebutuhan perusahaan secara konsisten dan meminimasi resiko yang berkaitan dengan pengadaan bahan baku maupun komponen. Oleh karena itu perusahaan harus memilih supplier dengan cermat dan tepat agar tidak merugikan perusahaan di masa yang akandating.Pemilihan supplier pada PT Cipta Arsigriya dilakukan oleh bagian purchasing dengan menindaklanjuti penawaran kerjasama dari supplier yang ditujukan kepada perusahaan. Dikarenakan untuk mempersingkat waktu proses pemilihan supplier selama ini hanya berdasarkan harga terendah dan metode pembayaran saja sehingga faktor-faktor lain menjadi terabaikan. Pengabaian faktor-faktor lain ini menyebabkan sering terjadi kendala khususnya dalam proses pembangunan hunian pada perusahaan.
\end{abstract}

Kata kunci: weigh Procuct, SPK, Bahan Bangunan

\section{Pendahuluan}

PT Cipta Arsigriya adalah sebuah perusahaan yang bergerak di bidang properti bangunan. Dalam usaha berkompetisi untuk memenangkan konsumen di dunia usaha sejenis PT Cipta Arsigriya selalu berusaha memberikan pelayanan dan hunian yang mampu menarik minat para konsumen. Salah satu pelayanan yang diberikan PT Cipta Arsigriya adalah waktu pembangunan yang berdurasi seminimal mungkin, untuk melakukan hal ini PT Cipta Arsigriya tentunya membutuhkan bantuan supplier untuk melakukan proses pembangunan sesuai jadwal yangdirencanakan.

Selama ini PT Cipta Arsigriya memiliki sekitar 50 supplier yang tersebar di berbagai macam bidang bahan bangunan seperti kayu, bata, batu dan lain sebagainya.
Karena banyaknya supplier yang menawarkan kerjasama kepada perusahaan maka perlu dilakukannya proses penyeleksiansupplier.

Pemilihan supplier merupakan salah satu hal yang penting dalam aktivitas pembelian bagi perusahaan, karena pemilihan supplier ini sangat berpengaruh pada kualitas dan ketersediaan suatu produk. Tujuan utama proses pemilihan supplier adalah untuk menentukan supplier yang memiliki efisiensi dalam memenuhi kebutuhan perusahaan secara konsisten dan meminimasi resiko yang berkaitan dengan pengadaan bahan baku maupun komponen[1]. Oleh karena itu perusahaan harus memilih supplier dengan cermat dan tepat agar tidak merugikan perusahaan di masa yang akandating.Pemilihan supplier pada PT Cipta Arsigriya dilakukan oleh bagian purchasing dengan 
menindaklanjuti penawaran kerjasama dari supplier yang ditujukan kepada perusahaan. Dikarenakan untuk mempersingkat waktu proses pemilihan supplier selama ini hanya berdasarkan harga terendah dan metode pembayaran saja sehingga faktor-faktor lain menjadi terabaikan. Pengabaian faktor-faktor lain ini menyebabkan sering terjadi kendala khususnya dalam proses pembangunan hunian pada perusahaan.

PT Cipta Arsigriya sering mengalami kendala salah satunya adalah terhambatnya proses pembangunan sesuai jadwal yang ditentukan karena keterlambatan supplier dalam memenuhi permintaan barang. Selain itu kualitas barang yang diterima dari supplier kurang baik dan sering terjadi keterlambatan dalam proses pengiriman barang sehingga perusahaan yang harus mengambil barang ke supplier. Karena banyaknya kendala yang terjadi akibat tidak adanya kriteria yang jelas maka diperlukan sebuah sistem pendukung keputusan untuk membantu proses pemilihan supplier.

Sistem pendukung keputusan dapat diartikan sebagai suatu sistem yang dirancang yang digunakan untuk mendukung manajemen di dalam pengambilan keputusan[2].Dalam merancang sebuah sistem pendukung keputusan yang baik diperlukan metode pengambilan keputusan yang tepat dan sesuai dengan permasalahan yang sedang terjadi. Salah satu metode dalam pengambilan keputusan yaitu Weighted Product yang akan digunakan penulis untuk menyelesaikan permasalahan dalam pemilihan supplier pada PT Cipta Arsigriya. Weighted Product (WP) merupakan metode pengambilan keputusan dengan cara perkalian untuk menghubungkan rating atribut, dimana rating setiap atribut harus dipangkatkan dulu dengan bobot atribut yang bersangkutan untuk mendapatkan hasilnya[3].

\section{Tinjauan Pustaka}

\subsection{Sistem Pendukung Keputusan}

Sistem adalah kumpulan dari objek-objek seperti orang, konsep, dan prosedur yang ditujukan untuk melakukan fungsi tertentu atau memenuhi suatu tujuan[4], Sistem pendukung keputusan dapat diartikan sebagai suatu sistem yang dirancang yang digunakan untuk mendukung manajemen di dalam pengambilan keputusan[5], Sistem pendukung keputusan adalah suatu sistem informasi spesifik yang ditujukan untuk membantu manajemen dalam mengambil keputusan yang berkaitan dengan persoalan yang bersifat semi terstuktur. Sistem ini memiliki fasilitas untuk menghasikan berbagai alternatif secara interaktif digunakan oleh pemakai[6].

\subsection{Metode Weight Product}

Metode Weighted Product (WP) merupakan salah satu metode sistem pendukung keputusan yang sederhana dengan perkalian untuk menghubungkan rating atribut, dimana setiap rating setiap atribut harus dipangkatkan dengan bobot atribut yang bersangkutan[7]. Metode Weighted Product (WP) merupakan bagian dari analisis multi-kriteria keputusan (Multi-Criteria Decision Analysis/MCDA) yang sangat terkenal. Metode multi-kriteia pengambilan keputusan Multi-Criteria Decision Making (MCDM)[8]. Metode Weighted Product (WP) membutuhkan proses normalisasi karena metode ini mengalikan hasil penilaian dari setiap atribut. Hasil perkalian tersebut belum bermakna jika belum dibandingkan (dibagi) dengan nilai standar. Bobot untuk atribut manfaat berfungsi sebagai pangkat positif dalam proses perkalian, sementara bobot biaya berfungsi sebagai pangkat negatif. Weighted Product (WP) merupakan metode pengambilan keputusan dengan cara perkalian untuk menghubungkan rating atribut, dimana rating setiap atribut harus dipangkatkan dulu dengan bobot atribut yang bersangkutan untuk mendapatkan hasilnya.Berikut adalah langkah-langkah dalam perhitungan metode Weighted Product (WP) yaitu :

a. Mengalikan seluruh atribut bagi seluruh alternatif dengan bobot sebagai pangkat positif bagi atributbiaya.

b. Hasil perkalian ditotal untuk menghasilkan nilai pada setiapalternatif.

c. Membagi nilai $\mathrm{V}$ pada setiap alternatif dengan nilai dari setiapalternatif.

d. Didapatkan urutan alternatif terbaik yang akan menjadikeputusan

$$
\begin{aligned}
& w_{j}=\frac{w_{j}}{\sum W} \\
& S_{i}=\prod_{i}^{n}=1 x_{i j}^{w j}
\end{aligned}
$$

Dimana

S : Menatakan preferensi alternatif dianalogikan sebagai vector S. x : Meyatakan nilai kriteria

w : Menyatakan nilai bobot kriteria i : Menyatakan alternatif

$\mathrm{j}$ : Menyatakan kriteria

$\mathrm{n}$ : Menyatakan banyaknya kriteria

wj: Menyatakan pangkat bernilai positif utuk atribut keuntungan, dan bernilai negatif untuk atribut biaya.

Preferensi relatif dari setiap alternatif, diberikan sebagai berikut :

$$
V_{i}=\frac{\prod_{j}^{n}=1 x_{i j}^{w j}}{\prod_{j}^{n}=1\left(X_{j *}\right) w j}
$$

\subsection{Supply Chain Management}

Supply Chain Management (SCM) adalah sebuah pendekatan untuk sistem integrasi yang efisien antara pemasok (supplier), pabrik (manufactur), pusat distribusi (wholesaler), pengecer (retailer) dan konsumen akhir, dimana produk yang telah diproduksi dan didistribusikan berada dalam jumlah yang benar dan tepat. Selain itu, lokasi yang tepat dan waktu yang tepat guna meminimalkan sistem biaya dan meningkatkan tingkat kepuasan pelayanan[9] 


\section{Metodologi Penelitian}

3.1 Metode Pengumpulan Data

Dalam pengumpulan data penelitian ini terdapat tiga metode yang dipakai yaitu observasi, wawancara dan studi pustaka.

a. Observasi.

Peneliti mengadakan pengamatan secara langsung di tempat penelitian untuk mendapatkan informasi mengenai aktivitas sistem yang berjalan saat ini yang sekiranya dapat dijadikan data tambahan dalam penelitian, lokasi dilakukannya observasi adalah di PT CiptaArsigriya.

b. Wawancara.

Peneliti melakukan wawancara kepada bagianbagian yang terlibat dalam proses pemilihan supplier yaitu bagian purchasing untuk mendapatkan informasi dengan cara mewawancarai narasumber secara langsung.

c. Studipustaka.

Penelitian ini dilakukan dengan cara mengumpulkan teori yang relevan dengan penelitian yang berasal dari literatur yang berkaitan dengan penelitian agar bisa menunjang hasil penulisan yang sedang dilakukan. Adapun pustaka yang digunakan berasal dari jurnal-jurnal yang didapat melalui internet dan buku-buku yang terkait dengan penelitianini.

\subsection{Penentuan Kriteria}

Berdasarkan pengamatan peneliti pemilihan supplier hanya berdasarkan harga terendah kurang tepat karena dalam mengevaluasi supplier terdapat banyak faktor yang perlu diperhatikan untuk memilih supplier yang terbaik, maka perlu adanya penambahan kriteria-kriteria yang dapat digunakan sebagai bahan pertimbangan dalam memilih supplier. Kriteria yang digunakan dalam pemilihan supplier bahan bangunan pada PT Cipta Arsigriya :

1. Quality(kualitas)

Kriteria quality adalah kriteria yang menilai supplier dari segi kualitas produk yang dihasilkan oleh supplier. Kriteria ini menilai apakah spesifikasi produk sesuai dengan yang dibutuhkan perusahaan.Kriteria kualitas meliputi :

a. Kesesuaian spesifikasi produk denganstandar. Apakah produk yang ditawarkan supplier memiliki jenis/spesifikasi yang sesuai dengan yang dibutuhkan perusahaan?

b. Kemampuan memberikan yangkonsisten.

kualitas

Seberapa konsisten supplier dalam memberikan kualitas produk yangbaik?

2. Cost (biaya)

Kriteria cost adalah kriteria yang berkaitan dengan biaya produk yang dimiliki supplier. Penilaian kriteria ini berdasarkan potongan harga dan jumlah pembelian minimal.Kriteria biaya meliputi: a. Pemberian potonganharga.

Apakah terdapat potongan harga yang diberikansupplier?

b. Jumlah pembelianminimal.

Adakah supplier memiliki standar jumlah pembelian minimal?

3. Delivery(pengiriman)

Kriteria delivery adalah kriteria yang menilai supplier dari segi pelayanan pengiriman produk. Penilaian kriteria ini berdasarkan layanan pengiriman yang diberikan oleh supplier.Kriteria pengiriman meliputi:

a. Ketepatan spesifikasi produk yangdikirim.

Apakah produk yang dikirim sesuai dengan lembar PO ?

b. Ketepatan waktupengiriman.

Apakah produk selalu dikirim sesuai tanggal yangdisepakati?

4. Flexibility(kemudahan)

Kriteria flexibility adalah kriteria yang menilai supplier dari kemampuan operasi untuk membuat perubahan kapasitas produksi untuk menyesuaikan perubahan yang terjadi.Kriteria kemudahan meliputi:

a. Kemudahan perubahan jumlahpesanan Apakah bisa melakukan perubahan jumlah pesanan kepada supplier?

b. Kemampuan perubahan waktupengiriman. Apakah bisa melakukan perubahan waktu pengiriman pesenan

5. Responsiveness (tanggungjawab)

Kriteria responsiveness adalah kriteria yang menilai supplier dari segi kemampuan supplier dalam merespon permasalahanyang terjadi. Penilaian dalam kriteria ini berdasarkan pemberian jaminan (respon) supplier terhadap produk jika terjadi permasalahan seperti,barang rusak dalam pengiriman, atau ketidaksesuaian jumlah ataupun spesifikasi produk. Kriteria tanggung jawab meliputi :

a. Mampu merespon masalah / complain dengan baik.

Bagaimana respon supplier terhadap keluhan?

b. Pemberian jaminan terhadap produk

Apakah supplier menjamin produk yang diterima tanpa cacat?

Setelah menentukan kriteria yang digunakan dalam penelitian ini diperlukan penentuan bobot dari masing-masing kriteria yang digunakan. Bobot ktiteria dalam penelitian ini ditentukan oleh user dalam hal ini adalah bagian purchasing pada PT Cipta Arsigriya. Pembobotan pada setiap kriteria mengacu pada Skala Likert yang diberi nilai antara 1 sampai 5 berdasarkan tingkat kepentingan, yaitu: $1=$ tidak penting $=1$, kurang penting $=2$, cukup penting $=3$, penting $=4$, sangat penting $=5$. Adapun bobot yang digunakan ditunjukan pada tabelberikut: 
Tabel 1. Penentuan Kriteria

\begin{tabular}{|c|c|c|c|c|}
\hline Kriteria & Bobot & Kode & $\begin{array}{l}\text { Sub } \\
\text { Kriteria }\end{array}$ & Ket \\
\hline \multirow[t]{2}{*}{ Kualitas } & \multirow[t]{2}{*}{5} & Q1 & $\begin{array}{l}\text { Kesuasuain } \\
\text { produk } \\
\text { dengan } \\
\text { standar }\end{array}$ & Benefit \\
\hline & & Q2 & $\begin{array}{l}\text { Kemampua } \\
\mathrm{n} \\
\text { memberikan } \\
\text { kualitas } \\
\text { yang } \\
\text { konsisten }\end{array}$ & Benefit \\
\hline \multirow[t]{2}{*}{ Biaya } & \multirow[t]{2}{*}{5} & $\mathrm{C} 1$ & $\begin{array}{l}\text { Pemberian } \\
\text { potongan } \\
\text { harga }\end{array}$ & Benefit \\
\hline & & $\mathrm{C} 2$ & $\begin{array}{l}\text { Jumlah } \\
\text { Pembelian } \\
\text { minimal }\end{array}$ & Cost \\
\hline \multirow[t]{2}{*}{ Pengiriman } & \multirow[t]{2}{*}{5} & D1 & $\begin{array}{l}\text { Ketepatan } \\
\text { spesfikasi } \\
\text { produk yang } \\
\text { dikirim }\end{array}$ & Benefit \\
\hline & & D2 & $\begin{array}{l}\text { Ketepatan } \\
\text { waktu } \\
\text { pengiriman }\end{array}$ & Benefit \\
\hline Kemudahan & 3 & F1 & $\begin{array}{l}\text { Kemudahan } \\
\text { perubahan }\end{array}$ & Benefit \\
\hline
\end{tabular}

Tabel 2 Penentuan Sub Kriteria

\begin{tabular}{|c|c|c|c|}
\hline Kriteria & Sub Kriteria & Ket & Nilai \\
\hline \multirow[t]{3}{*}{ Q1 } & \multirow[t]{3}{*}{$\begin{array}{l}\text { Apakah produk yang ditawarkan supplier } \\
\text { memiliki jenis/spesifikasi yang sesuai dengan } \\
\text { yang dibutuhkanperusahaan }\end{array}$} & $\begin{array}{l}\text { Semua produk supplier sesuai dengan } \\
\text { kebutuhan }\end{array}$ & 5 \\
\hline & & $\begin{array}{l}\text { Tidak semua produk supplier sesuai dengan } \\
\text { kebutuhan }\end{array}$ & 3 \\
\hline & & $\begin{array}{l}\text { Produk supplier tidak sesuai dengan } \\
\text { kebutuhan }\end{array}$ & 1 \\
\hline \multirow[t]{3}{*}{ Q2 } & \multirow{3}{*}{$\begin{array}{l}\text { Seberapa konsisten supplier dalam memberikan } \\
\text { kualitas produk yang baik }\end{array}$} & Konsisten & 5 \\
\hline & & Tidak Konsisten & 3 \\
\hline & & Belum diketehui & 1 \\
\hline \multirow[t]{4}{*}{ C1 } & \multirow{4}{*}{$\begin{array}{l}\text { Apakah terdapat potongan harga yang diberikan } \\
\text { supplier }\end{array}$} & Di atas $10 \%$ & 5 \\
\hline & & $5 \%-10 \%$ & 4 \\
\hline & & Di bawah $5 \%$ & 3 \\
\hline & & Tidak ada & 1 \\
\hline \multirow[t]{3}{*}{$\mathbf{C 2}$} & \multirow{3}{*}{$\begin{array}{l}\text { Adakah supplier memiliki standar jumlah } \\
\text { pembelianminimal }\end{array}$} & Ada & 1 \\
\hline & & Ada namun tidak semua produk & 3 \\
\hline & & Tidak ada & 5 \\
\hline \multirow[t]{4}{*}{ D1 } & \multirow{4}{*}{$\begin{array}{l}\text { Apakah produk yang dikirim sesuai dengan } \\
\text { lembarPO }\end{array}$} & Produk yang dikirim selalu sesuai PO & 5 \\
\hline & & Produk yang dikirim tidak selalu sesuai PO & 3 \\
\hline & & Produk yang dikirim tidak sesuai PO & 2 \\
\hline & & Belum Diketahui & 1 \\
\hline \multirow[t]{4}{*}{ D2 } & \multirow{4}{*}{$\begin{array}{l}\text { Apakah produk selalu dikirim sesuai tanggal } \\
\text { yangdisepakati }\end{array}$} & Produk selalu dikirim tepat waktu & 5 \\
\hline & & Produk tidak selalu dikirim tepat waktu & 3 \\
\hline & & Produk tidak dikirim tepat waktu & 2 \\
\hline & & Belum Diketahui & 1 \\
\hline
\end{tabular}




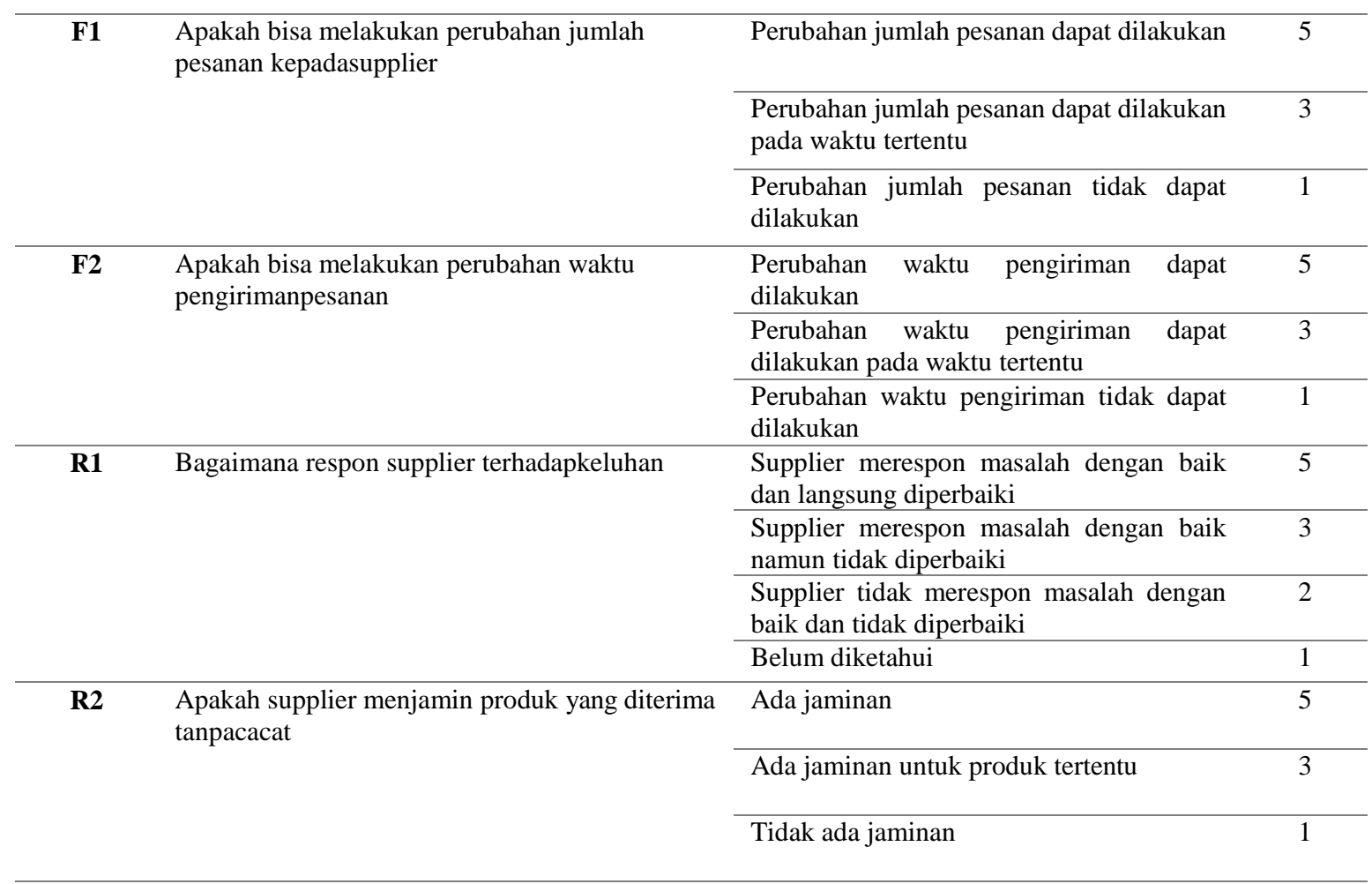

\section{Hasil dan Pembahasan}

4.1 Menghitung Normalisasi Bobot dari setiap Kriteria Setelah didapatkan nilai bobot dari masing-masing kriteria, kemudian dalam penggunaan metode Weighted Product (WP) membutuhkan proses normalisasi bobot karena metode ini mengalikan hasil penilaian dari setiap atribut. Proses normalisasi dilakukan dengan membagi bobot kriteria dengan keseluruhan total bobot, sehingga total bobot $\sum \mathrm{Wj}=1$. Berikut rumus perhitungan bobot kriteria:

$$
w_{j}=\frac{w_{j}}{\sum w_{j}}
$$

Dimana:

Wj : Bobot untuk kriteria ke $\mathrm{j}$

$\sum \mathrm{Wj} \quad$ : Total bobot seluruh kriteria

Dari normalisasi yang dilakukan maka didapatkan hasil sebagai berikut :

Tabel 3 Norbalisasi Bobot dari Setiap Kriteria

\begin{tabular}{|c|c|c|c|}
\hline No & Kriteria & $\begin{array}{l}\text { Bobo } \\
\text { t }\end{array}$ & Normalisasi \\
\hline Q1 & $\begin{array}{l}\text { Kesesuaian spesifikasi } \\
\text { produk dengan standar. }\end{array}$ & 5 & $\begin{array}{l}5 / 44= \\
0.113636364\end{array}$ \\
\hline Q2 & $\begin{array}{l}\text { Kemampuan } \\
\text { memberikan kualitas } \\
\text { yang } \\
\text { konsisten. }\end{array}$ & 5 & $\begin{array}{l}5 / 44= \\
0.113636364\end{array}$ \\
\hline C1 & $\begin{array}{l}\text { Pemberian potongan } \\
\text { harga. }\end{array}$ & 5 & $\begin{array}{l}5 / 44= \\
0.113636364\end{array}$ \\
\hline $\mathrm{C} 2$ & $\begin{array}{l}\text { Jumlah pembelian } \\
\text { minimal. }\end{array}$ & 5 & $\begin{array}{l}5 / 44= \\
0.113636364\end{array}$ \\
\hline
\end{tabular}

\begin{tabular}{llll}
\hline D1 & $\begin{array}{l}\text { Ketepatan spesifikasi } \\
\text { produk yangdikirim. }\end{array}$ & 5 & $\begin{array}{l}5 / 44= \\
0.113636364\end{array}$ \\
\hline D2 & Ketepatan waktu & 5 & $5 / 44=$ \\
& $\begin{array}{l}\text { pengiriman. } \\
\text { F1 }\end{array}$ & & 0.113636364 \\
& Kemudahan perubahan & 3 & $\begin{array}{l}3 / 44= \\
\text { jumlah pesanan }\end{array}$ \\
& & 0.06818181 \\
& & 8 \\
\hline F2 & Kemampuanperubahanw & 3 & $3 / 44=$ \\
& aktupengiriman. & & 0.06818181 \\
& & & 8 \\
\hline R1 & Mampu merespon & 4 & $4 / 44=$ \\
& masalah/ & & 0.09090909 \\
& komplaindengan baik. & & 1 \\
\hline R2 & Pemberian jaminan & 4 & $4 / 44=$ \\
& terhadap produk. & & 0.09090909 \\
& & & 1
\end{tabular}

4.2 Menentukan Nilai Kriteria Untuk Setiap Alternatif Setelah nornalisasi bobot didapatkan, maka selanjutnya menentukan nilai kriteria untuk setiap alternatif. 
Tabel 4 Nilai Kriteria Untuk Setiap Alternatif

\begin{tabular}{|c|c|c|c|c|c|c|c|c|c|c|}
\hline \multirow[t]{2}{*}{ Alternatif } & \multicolumn{2}{|c|}{ C1 } & \multicolumn{2}{|c|}{ C2 } & \multicolumn{2}{|c|}{ C3 } & \multicolumn{2}{|c|}{ C4 } & \multicolumn{2}{|c|}{ C5 } \\
\hline & Q1 & Q2 & $\mathrm{C} 1$ & $\mathrm{C} 2$ & D1 & D2 & F1 & $\mathrm{F} 2$ & R11 & Q2 \\
\hline A1 & 3 & 5 & 1 & 5 & 5 & 3 & 5 & 5 & 5 & 3 \\
\hline A2 & 3 & 3 & 3 & 5 & 5 & 5 & 3 & 3 & 5 & 3 \\
\hline A3 & 3 & 3 & 1 & 3 & 5 & 5 & 5 & 5 & 3 & 1 \\
\hline A4 & 3 & 5 & 4 & 3 & 3 & 3 & 3 & 3 & 5 & 5 \\
\hline A5 & 3 & 3 & 4 & 3 & 3 & 5 & 5 & 5 & 3 & 3 \\
\hline A6 & 5 & 5 & 1 & 1 & 5 & 2 & 3 & 5 & 2 & 1 \\
\hline A7 & 5 & 5 & 3 & 3 & 3 & 3 & 3 & 3 & 5 & 1 \\
\hline A8 & 3 & 3 & 4 & 5 & 5 & 3 & 3 & 3 & 5 & 1 \\
\hline A9 & 3 & 3 & 1 & 1 & 3 & 3 & 5 & 5 & 5 & 3 \\
\hline A10 & 3 & 3 & 3 & 3 & 5 & 5 & 3 & 5 & 3 & 3 \\
\hline A11 & 3 & 3 & 1 & 3 & 5 & 3 & 3 & 3 & 5 & 1 \\
\hline A12 & 3 & 5 & 3 & 3 & 5 & 3 & 3 & 5 & 5 & 1 \\
\hline A13 & 5 & 3 & 4 & 1 & 5 & 3 & 3 & 3 & 5 & 5 \\
\hline A14 & 3 & 3 & 1 & 5 & 3 & 3 & 3 & 1 & 3 & 3 \\
\hline A15 & 5 & 5 & 5 & 1 & 3 & 3 & 1 & 1 & 5 & 1 \\
\hline A16 & 5 & 5 & 1 & 5 & 5 & 5 & 3 & 3 & 5 & 1 \\
\hline A17 & 5 & 5 & 1 & 5 & 5 & 5 & 5 & 5 & 5 & 1 \\
\hline A18 & 5 & 3 & 3 & 5 & 5 & 5 & 3 & 3 & 1 & 1 \\
\hline A19 & 5 & 5 & 4 & 5 & 5 & 3 & 1 & 1 & 1 & 5 \\
\hline A20 & 5 & 3 & 3 & 3 & 5 & 3 & 3 & 3 & 1 & 3 \\
\hline
\end{tabular}

4.3 Menghitung Nilai Vektor S

Menentukan nilai vector s dari masing-masing alternatif dapat dilakukan dengan menggunakan persamaan 2 dengan hasil seperti pada tabel 5 berikut ini:

Tabel 5 Nilai Vektor Tiap Alternatif

dapat dilakukan dengan menggunakan persaman
dengan hasil seperti pada tabel 5 berikut ini:
tabel 6 sebagai berikut.

Tabel 6 Hasil Keseluruhan Nilai Vektor S

4.4 Menentukan Nilai Vektor V

Setelah nilai vektor $\mathrm{S}$ didapat, maka selanjutnya menjumlahkan vektor $S$ untuk menentukan nilai dari vektor $\mathrm{V}$ dengan menggunakan rumus persamaan (3) Berikut hasil perhitungan nilai vector $\mathrm{V}$ seperti pada tabel 7 sebagai berikut. 
Tabel 7 Nilai Vektor V

\begin{tabular}{|c|c|c|c|c|}
\hline No & Supplier & Vektor S & $\sum$ Vektor S & $\begin{array}{c}\text { Vektor } \mathbf{V}= \\
\text { Vektor } \mathrm{S} / \sum \text { Vektor } \mathrm{S}\end{array}$ \\
\hline 1 & A1 & 3.53 & \multirow[t]{12}{*}{63.1} & 0.056090403 \\
\hline 2 & $\mathrm{~A} 2$ & 3.74 & & 0.05927271 \\
\hline 3 & A3 & 2.88 & & 0.045723109 \\
\hline 4 & A4 & 3.60 & & 0.057121587 \\
\hline 5 & A5 & 3.52 & & 0.055810541 \\
\hline 6 & A6 & 2.34 & & 0.038017433 \\
\hline 7 & A7 & 3.19 & & 0.050613928 \\
\hline 8 & A8 & 3.30 & & 0.052295898 \\
\hline 9 & A9 & 2.62 & & 0.04159489 \\
\hline 10 & A10 & 3.49 & & 0.055284411 \\
\hline 11 & $\ldots \ldots$ & $\ldots \ldots$ & & $\ldots \ldots$ \\
\hline 20 & A20 & 3.05 & & 0.048317224 \\
\hline
\end{tabular}

\subsection{Melakukan Perangkingan}

Setelah mendapatkan nilai vektor V dari setiap alternatif maka selanjutnya dapat dilakukan perengkingan nilai vektor V dimana supplier yang terpilih adalah supplier Berikut beberapa saran yang penulis sampaikan pada yang memiliki nilai $\mathrm{V}$ terbesar. Hasil perengkingan yang penelitian ini yaitu :

telah dilakukan adalah seperti pada tabel 8 sebagai berikut :

Tabel 8 Perangkingan

\begin{tabular}{|c|c|c|c|}
\hline No & $\begin{array}{l}\text { Hasil } \\
\text { Akhir }\end{array}$ & Nilai & Keterangan \\
\hline 1 & A1 & 0.05927271 & Rangking 1 \\
\hline 2 & A2 & 0.057121587 & Rangking 2 \\
\hline 3 & A3 & 0.057007773 & Rangking 3 \\
\hline 4 & $\mathrm{~A} 4$ & 0.056090403 & Rangking 4 \\
\hline 5 & A5 & 0.055810541 & Rangking 5 \\
\hline 6 & A6 & 0.055284411 & Rangking 6 \\
\hline 7 & A7 & 0.053430843 & Rangking 7 \\
\hline 8 & A8 & 0.053171875 & Rangking 8 \\
\hline 9 & A9 & 0.05240782 & Rangking 9 \\
\hline 10 & A10 & 0.052295898 & Rangking 10 \\
\hline 11 & $\cdots$ & ................. & . \\
\hline 20 & A20 & 0.038017433 & Rangking 20 \\
\hline
\end{tabular}

\section{Kesimpulan}

Berdasarkan dari hasil penelitian diatas maka dapat disimpulan bahwa :

1. Dalam penyelesaian kasus di atas penulis menggunakan model QCDR yaitu Quality, Cost, Delivery, Flexibility, Responsivenes.
2. Dari hasil penelitian didapatkan bahwa Gudang Delima memiliki nilai skor tertinggi yaitu 0,05927271

1. Perlu dilakukan perbandingan hasil dengan menggunakan metode yang berbeda guna menghasilkan perbandingan metode yang dipakai.

2. Sistem dapat dikembangkan ke konsep Group Decission suport system. Sehingga hasil rekomendasi akan lebih baik lagi.

\section{Daftar Rujukan}

[1] A. Revi, I. Parlina, and S. Wardani, "Analisis Perhitungan Metode MOORA dalam Pemilihan Supplier Bahan Bangunan di Toko Megah Gracindo Jaya," InfoTekJar (Jurnal Nas. Inform. dan Teknol. Jaringan), vol. 3, no. 1, pp. 95-99, 2018.

[2] S. Manurung, "Sistem Pendukung Keputusan Pemilihan Guru Dan Pegawai Terbaik Menggunakan Metode Moora," J. SIMETRIS, vol. 9, no. 1, pp. 701-706, 2018.

[3] V. Listyaningsih, H. Setiawan, E. Sudrajat, and R. P. Kristianto, "DSS Pemilihan Penerima Bantuan Perbaikan Rumah dengan Metode Weight Product (WP)," Semin. Nas. Teknol. Inf. dan Multimed., no. October 2017, pp. 6-7, 2016.

[4] S. Y. Hutagalung, F. Pratiwi, and I. Wijaya, "Penerapan Metode Weighted Aggregated Sum Product Assesment ( WASPAS ) Dalam Keputusan Penerimaan Beasiswa," pp. 148- 
151,2018

[5] A. Y. Saputra, Y. Primadasa, P. Sisteminformasi, and K. T. Pengajar, "Penerapan Metode Moora Dalam Pemilihan Sekolah Dasar," SISTEMASI, vol. 8, pp. 305312, 2019.

[6] Y. Primadasa and V. Amalia, "Penerapan Metode Multi Factor Evaluation Process untuk Pemilihan Tanaman Pangan di Kabupaten Musi Rawas," J. Sisfo, vol. 07, no. 01, pp. 47-58, 2017.

[7] S. Barus, V. M. Sitorus, D. Napitupulu, M. Mesran, and S. Supiyandi, "Sistem Pendukung Keputusan Pengangkatan Guru Tetap Menerapkan Metode Weight Aggregated Sum Product Assesment ( WASPAS )," Media Inform. Budidarma, vol. 2, no. 2, pp. 10-15, 2018.

[8] F. Wikipedia, "Weighted product model," no. Mcdm, pp. 4-6, 2017.

[9] Zulkifli, "Rancangan Bangun Website ELearning Dengan Pemodelan UML," Intecoms J. Inrmation Technol. anda Comput. Sci., vol. 1, no. 1, pp. 430-439, 2018. 